\title{
ANATOMICAL VARIATIONS OF THE HUMAN THORACIC DUCT
}

\section{Bapuji. P ${ }^{1}$, Srinivasarao Yalakurthi ${ }^{* 2}$, Thirupathirao Vishnumukkala ${ }^{3}$, Swayam Jothi Dorai Raj ${ }^{4}$.}

${ }^{1}$ Professor \& Head, Department of Anatomy, ASRAM Medical college, Eluru, India.

${ }^{* 2}$ Assistant Professor, Department of Anatomy, ASRAM Medical College, Eluru, India.

${ }^{3}$ Lecturer of Anatomy, PU-RCSI School of Medicine, Perdana University, Malaysia.

${ }^{4}$ Professor \& Head, Department of Anatomy, SSSMCRI, Nellikuppam, India.

\section{ABSTRACT}

Background and Aims: The thoracic duct is the major lymphatic duct in the human body, the variations in the origin, course and termination of the thoracic duct are of great clinical importance during surgeries related to the upper abdomen, posterior mediastinum and in cervical region, but still now a detailed study had not been done in Andhra Pradesh state, it was decided to undertake this present study. Isolation of the thoracic duct and tracing the origin, course and termination were done to know more about it than already documented and thereby hoping to add more information to guide the radiologists and operating surgeons.

Materials and methods: A total number of 45 cadavers were studied, of these 15 were female and 30 were male cadavers. The material consisted of adult cadavers between the ages of 42-81 from the dissection halls of department of anatomy of 3 different medical colleges in costal Andhra Pradesh.

Results: The observations of the formation, course, length, vertebral levels, types of cisterna chili, and variations in the termination in cervical region are documented in this study. Conclusion: The present findings showed a great variability compare the previous studies. The findings noted in the present study regarding thoracic duct had contributed to a better understanding of the anatomy of the thoracic duct and will prove definitely useful to surgeons during surgical procedures related to the thoracic duct.

KEY WORDS: Cisterna Chyli. Thoracic duct, Variations.

Address for Correspondence: Mr. Srinivasarao Yalakurthi, Assistant Professor, Department of Anatomy, ASRAM Medical College, Eluru, India. E-Mail: Srinivasaraoyalakurthi@gmail.com

Access this Article online

Quick Response code

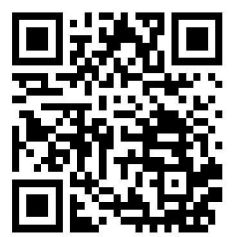

DOI: $10.16965 /$ ijar.2018.362

Journal Information

International Journal of Anatomy and Research

ICV for 2016 ISSN (E) 2321-4287 | ISSN (P) 2321-8967

https://www.ijmhr.org/ijar.htm

DOI-Prefix: https://dx.doi.org/10.16965/ijar

Article Information

Received: 16 Aug 2018

Peer Review: 16 Aug 2018

Revised: None
Accepted: 03 Oct 2018

Published (O): 05 Nov 2018

Published (P): 05 Nov 2018

\section{INTRODUCTION}

Thoracic duct is the largest lymphatic channel draining the lymph and chyle from whole of the body below the diaphragm and left side of the body above the diaphragm. It arises in a dilatation, the cistern chyli, in the upper abdomen deep to the right crus of the diaphragm. It passes through the aortic opening to the right of the aorta, ascends in the posterior mediastinum between the vertebral column and oesophagus with the descending thoracic aorta on left side and azygos vein on the right side, in close relation to the splanchnic nerves on either side .It crosses from the right side to the left with varying degrees of obliquity at the level of the $\mathrm{T}_{4}-\mathrm{T}_{5}$. It reaches the root of the neck, where it arches from behind the left common carotid artery, to open into the left brachiocephalic vein 
at the junction between the left internal jugular and left subclavian veins [1].

Throughout its length it gives a beaded appearance due to the presence of valves. The lymph in the thoracic duct often has a milky appearance because of the fine droplets of the fat as a result of the intestinal lymph [2].

Any variations of thoracic duct are of utmost importance to a thoracic surgeon, because of its vulnerability of damage during any surgical procedures [3].

The trauma to the chest by blunt objects producing fracture, fracture and dislocation of vertebra, stab wounds in the vicinity of the vertebral column may lead to rupture of the thoracic duct. Chronic inflammatory conditions like tuberculosis of lung, fungal infections, sarcoidosis and other granulomatous diseases involving the posterior mediastinal lymph nodes may cause compression or obstruction of the thoracic duct as its sequelae. The neoplasms of the thoracic viscera may by direct spread compress the thoracic duct. The neoplasms of the abdominal viscera are known to produce metastasis in the cervical lymph nodes, especially on the left side, producing a lump which may be the only sign indicating malignancy of the abdominal viscera. As a consequence of obstruction and rupture of the thoracic duct, conditions like chylothorax, chylous ascites, chyluria and chylous fistula are produced, which are often fatal [4].

With the recent advances in radio imaging techniques like ultrasonography, computerized tomographic scanning, MRI, lymphangiography and lymphoscintiography and also catheterization of the thoracic duct are being successfully under taken to demonstrate the course of the thoracic duct [5].

Thorough knowledge of the relations of the structures in the posterior mediastinum will help us to have correct interpretation of the computerized tomographic scans and magnetic resonance imaging scans.

The thoracic duct is the largest lymph channel which could be traced. Since it is at danger in number of injuries and operations in the region of the posterior mediastinum detailed study of its formation, course and termination were made. The common pattern and variations are studied in a detailed manner to help the surgeons and thereby to prevent complications.

\section{MATERIALS AND METHODS}

A total number of 45 cadavers were studied, of these 15 were female and 30 were male cadavers. The material consisted of adult cadavers between the ages of 42-81 from the dissection halls of Departments of Anatomy of ASRAM, Eluru, Andhra Pradesh, Department of Anatomy of PIMS, Ganavaram, A.P. and Department of Anatomy of KIMS, Amalapuram. The study was carried in the dissection halls of the above colleges.

During routine dissection of thorax, abdomen and head \& neck region part of the work was done in the particular region whenever the dissection was in progress. The observations were neatly taken by 8.1 Mega pixel of Nikon camera. The findings observed regarding thoracic duct was documented in a schematic manner as for the proforma enclosed.

\section{OBSERVATIONS}

Observations made on different parts of the thoracic duct were documented.

Cisterna chyli: In the present study presence or absence of cisterna chyli was observed in adult cadavers both male and female. Cisterna chyli was present in $6(40 \%)$ out of 15 female bodies, and $14(46.6 \%)$ out of 30 male bodies. To sum up cisterna chyli was present in 20 (44.4\%) out 45 cadavers dissected (44.4\%) (Fig.1).

The position of the cisterna chyli was varying. The position of the cisterna chyli was at $\mathrm{L}_{1}-\mathrm{T}_{12}$ vertebrae in 10 adult cadavers (Fig. 2 ). The position of the cisterna chyli was at $T_{12}-T_{11}$ vertebrae in 6 adult cadavers (Fig. 3). The position of the cisterna chyli was at $L_{2}-L_{1}$ vertebrae in 4 adult cadavers (Fig 4).

Thoracic duct: The thoracic duct was found in every cadaver. The beginning of the thoracic duct conformed to three of the four types reported, depending on how the lumbar and intestinal trunks combined in the abdominal part. In type 9 cadavers (20\%) the thoracic duct arose from the confluence of the lumbar and intestinal trunk (Type I) (Fig 5). In 27 cadavers (60\%) 
it was formed by the confluence of two ascending lumbar lymph trunks and intestinal trunk joined the thoracic duct (Type II) (Fig. 6). In 9 cadavers (20\%) the thoracic duct ascended from a plexus formed by the lumbar and intestinal trunks (Type III) (Fig. 7).

Course of the thoracic duct: In the present study thoracic duct showed duplication in its course and united later. The extent of duplication varied from the height of single vertebral body to that of four or five. In 11 cadavers duplication was related to the single vertebral body (Fig. 8), in 10 cadavers, related to two vertebral bodies (Fig. 9), in 24 cadavers related to three vertebral bodies. In one specimen from a male cadaver duplication persisted in its distal part giving rise to 2 thoracic ducts (Fig. 10).

The thoracic duct was always passing through the aortic hiatus on the right of the aorta to enter the thorax. In the posterior mediastinum it was ascending in front of the vertebral column on the right side of the midline, between azygos and aorta, deep to the oesophagus up to the level of the body of 6 th or 7 th thoracic vertebra. There, it was crossing to left side of the midline with varying degrees of obliquity. The obliquity present was measured in terms of the heights of the vertebral bodies. It was crossing from the 6th thoracic vertebra to the 4 th thoracic vertebra in 18 cadavers (40\%) (Fig. 11), from the 6 th thoracic vertebra to the 3rd thoracic vertebra in 9 cadavers (20\%) (Fig. 12), from 7th thoracic vertebra to 4 th thoracic vertebra in 11 cadavers $(24.4 \%)$ and from the 7 th thoracic vertebra to the 3 rd thoracic vertebra in 7 cadavers (15.5\%) (Fig.13).

Length of the thoracic duct: In the present work the length of the thoracic duct was ranging from 36 to $43 \mathrm{cms}$ in the adult subjects. An attempt was made to find out the presence of any difference in length of the thoracic duct depending on the sex of the individual. In 18 out of 30 male cadavers dissected the length of the thoracic duct ranged between 35 to $40 \mathrm{cms}$, amounting to $60 \%$. In rest of the 12 the length was ranging between 41 to $45 \mathrm{cms}$, amounting to $40 \%$. Similarly in 12 out of 30 adult females dissected, the length was ranging between 35 to $40 \mathrm{cms}$, about $80 \%$.
In rest of the three females the length was ranging between 41 to $45 \mathrm{cms}$, amounting to $20 \%$.

Termination of the thoracic duct: In the present observation thoracic duct drained into the left internal jugular vein in 19 specimens (42.2\%) (Fig. 14) out of 45 specimens, and it terminated into the left jugulo-subclavian junction in 18 specimens (40\%) (Fig. 15), and it terminated into the left subclavian vein in 4 specimens $(8.8 \%)$ (Fig.16). Multiple terminations were observed in 4 specimens $(8.8 \%)$ out of 45 specimens (Fig. 17).

Fig. 1: Presence of the cisterna chili.

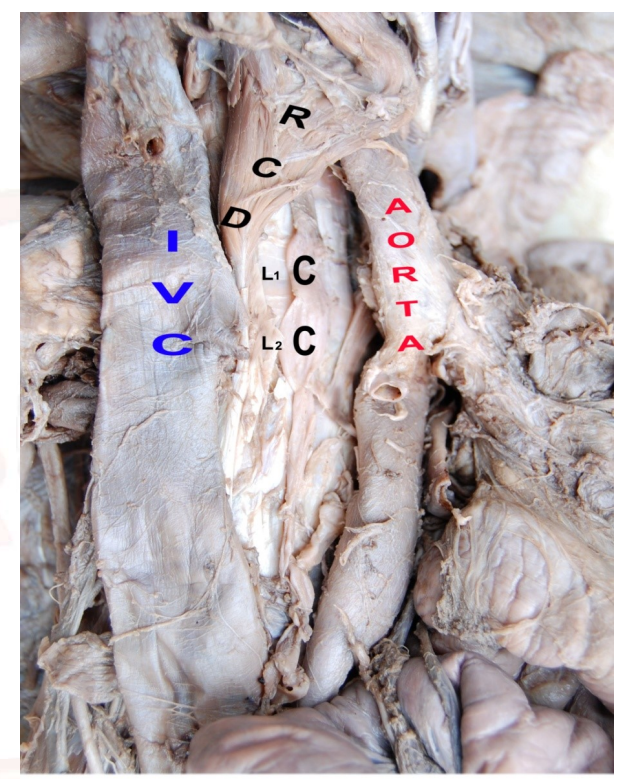

IVC-INFERIOR VENACAVA, CC-CISTERNA CHYLI, RCA-RIGHT CRUS OF THE DIAPHRAGM L-LUMBAR VERTEBRAE.

Fig. 2: The position of the cisterna chyli at L1-T12 vertebrae.

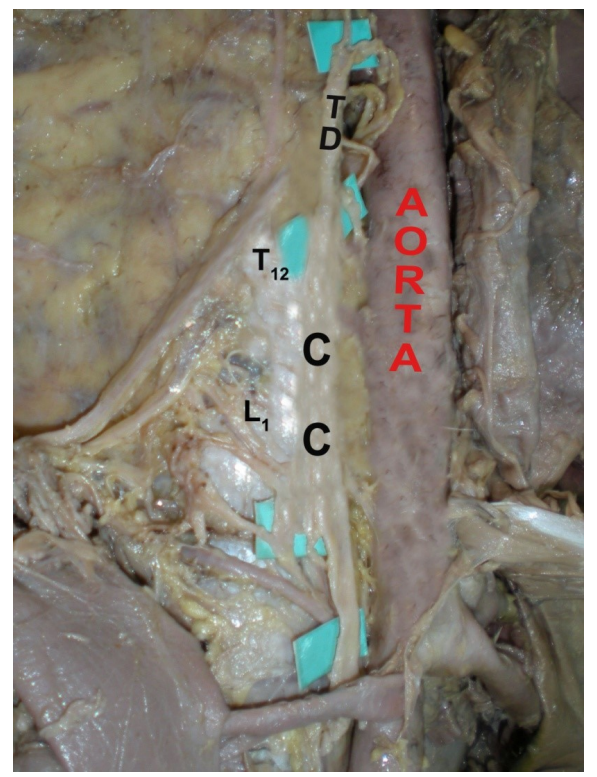

TD- THORACIC DECT, CC-CISTERNA CHYLI,T-THORACIC VERTEBRAE L-LUMBAR VERTEBRAE 
Fig. 3: The position of cisterna chyli at T12-T11 vertebrae.

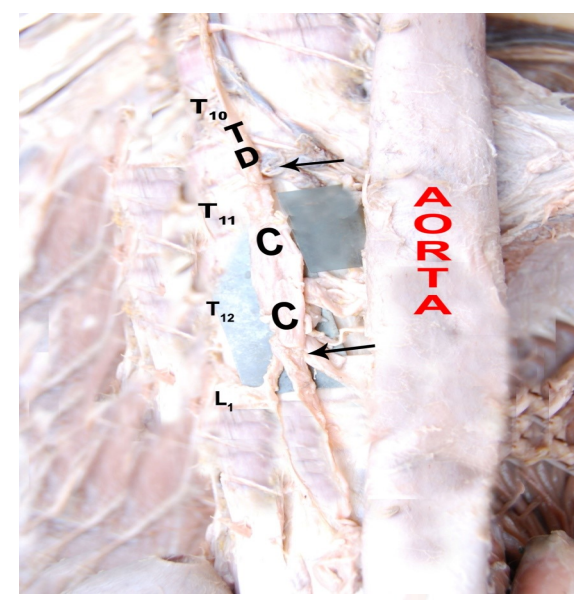

TD-THORACICDUCT, CC-CISTERNA CHYLI, T-THORACIC VERTEBRAE, L-LUMBAR VERTEBRAE

Fig. 4: The position of the cisterna chyli at L2-L1 vertebrae.

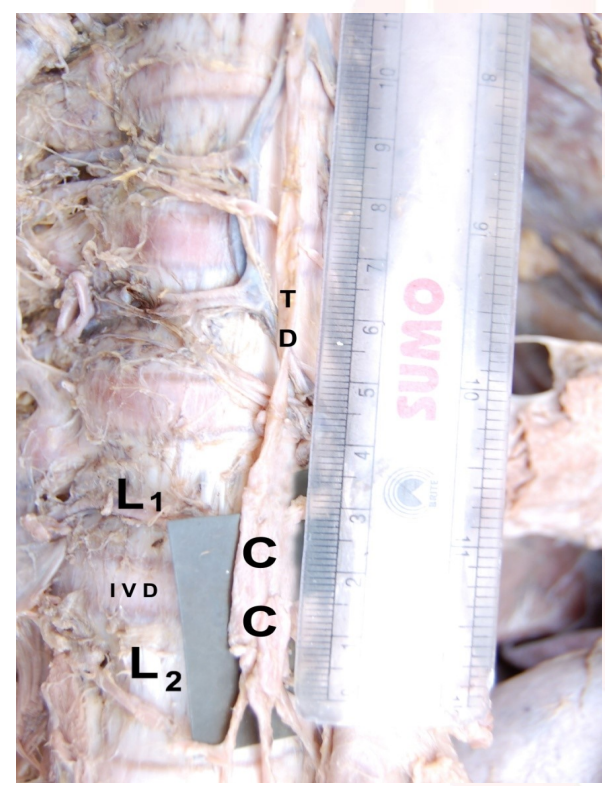

TD-THORACIC DUCT, CC-CISRETNA CHYLI, L-LUMBAR VERTEBRAE, IVD-INTER VERTEBRAL DISC

Fig. 5: Beginning of the thoracic duct-TYPE-I

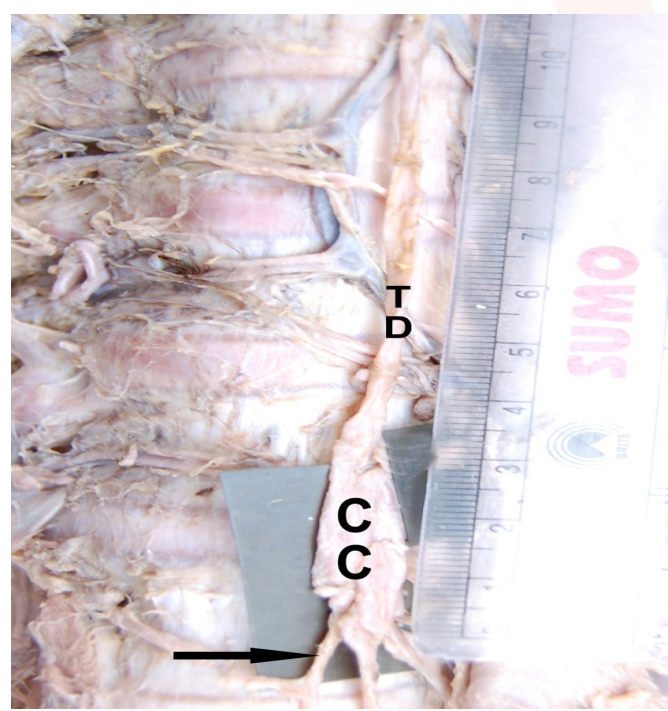

CC-CISTERNA CHYLI, VC-VERTEBRAL COLUMN, TDTHORACIC DUCT

Int J Anat Res 2018, 6(4.2):5861-68. ISSN 2321-4287
Fig. 6: Beginning of the thoracic duct TYPE-II.

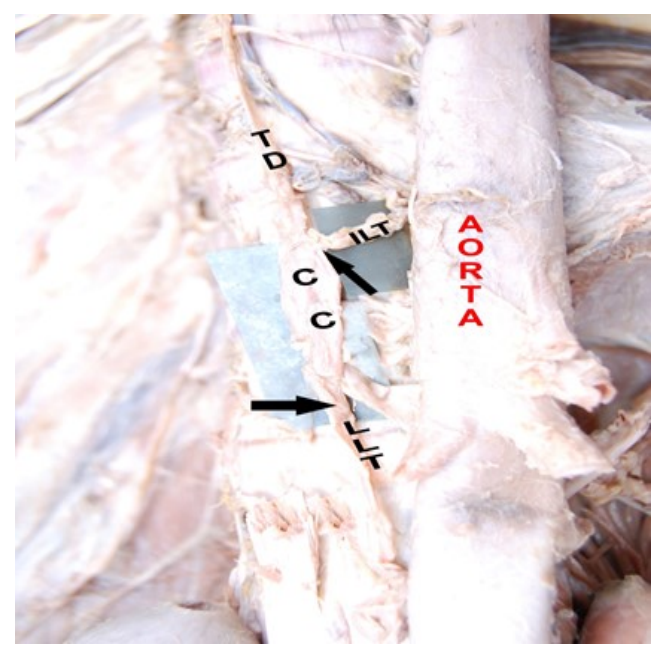

TD-THORACIC DUCT, CC-CISTERNA CHYLI, ILT-INTESTINAL LYMPH TRUNK, LLT-LUMBAR LYMPH TRUNK

Fig. 7: Beginning of the thoracic duct TYPE-III.

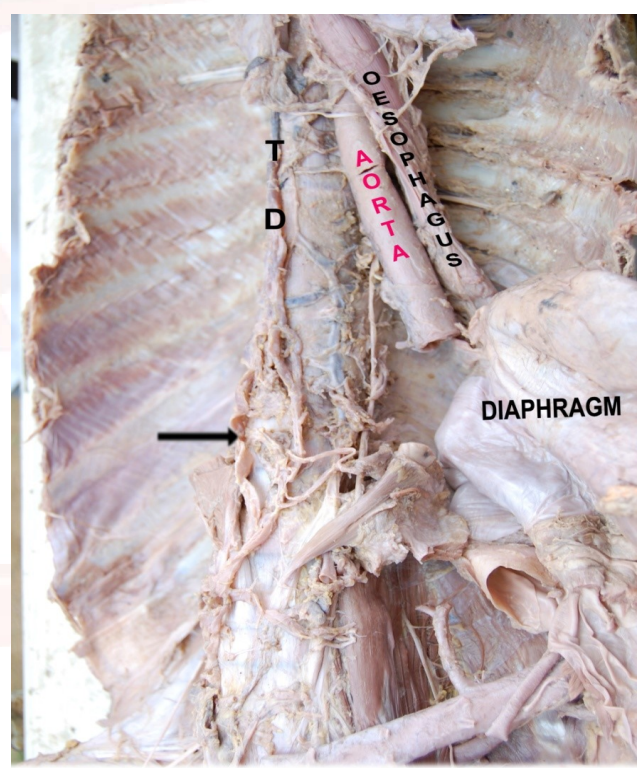

TD- THORACIC DUCT

Fig. 8: Extent of duplication-single vertebral level

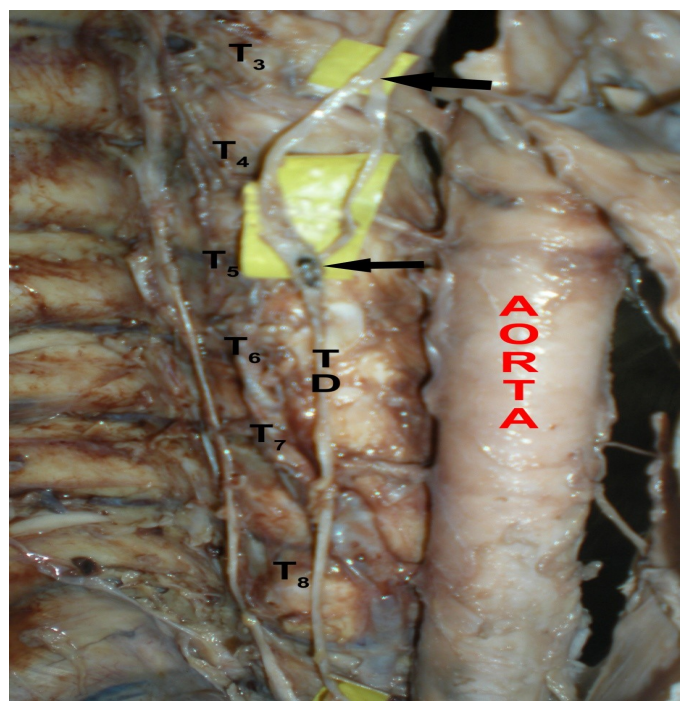

TD-THORACIC DUCT 
Fig. 9: Extent of duplication-two vertebral level.

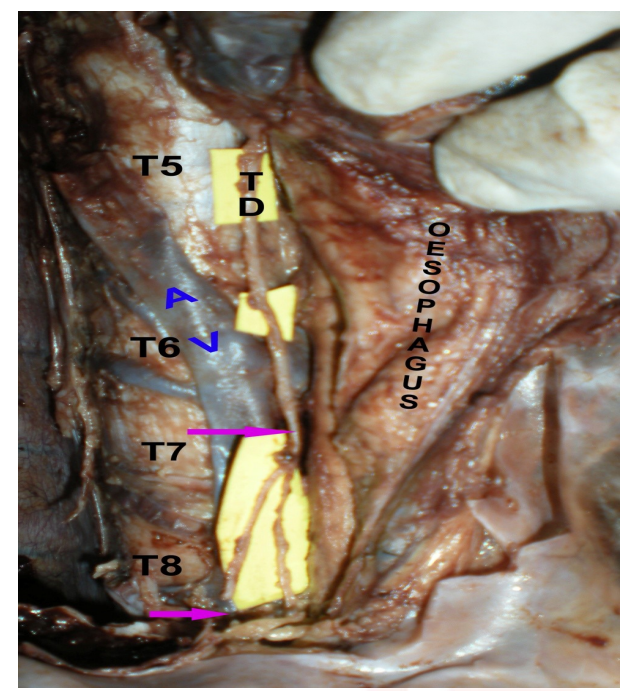

TD-THORACIC DUCT, AV-AZYGOS VEIN, T-THORACIC VERTEBRAE

Fig. 10: Two thoracic ducts.

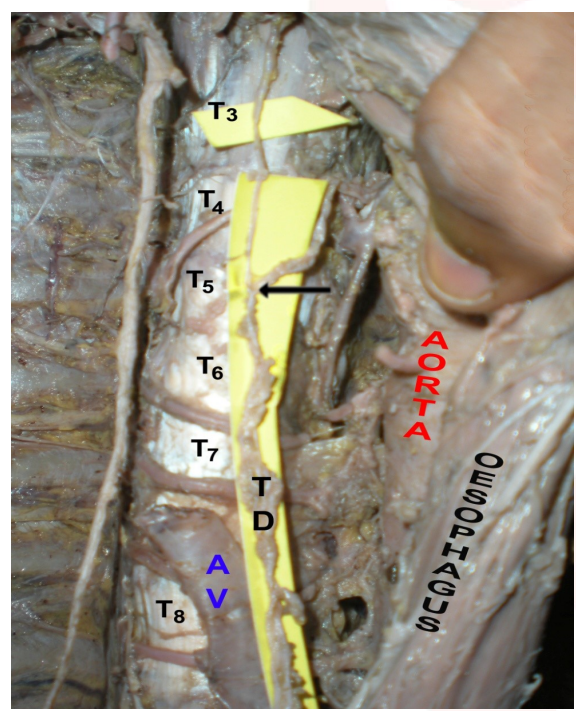

TD-THORACIC DCT, AV-AZYGOS VEIN, T-THORACIC VERTEBRAE

Fig. 11: Crossing of the thoracic duct from T6 TO T4 vertebrae.

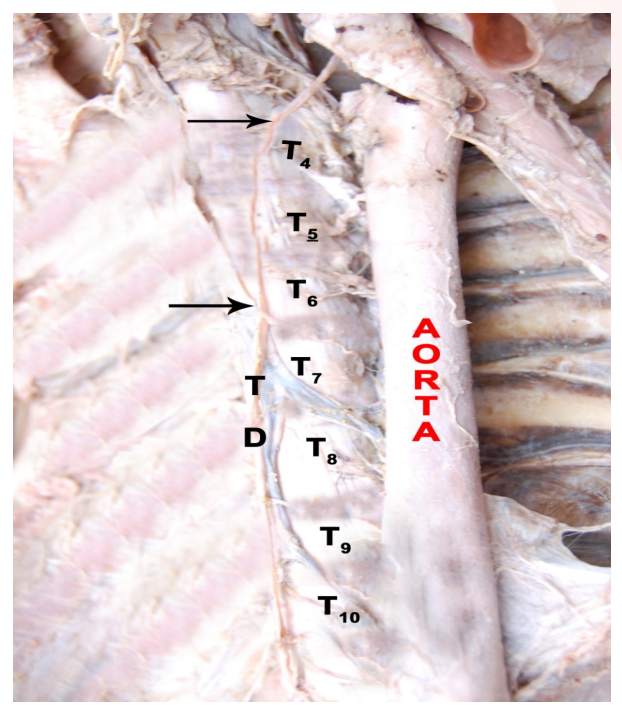

TD-THORACIC DUCT, T-THORACIC VERTEBRAE
Fig. 12: T6-T3 vertebra.

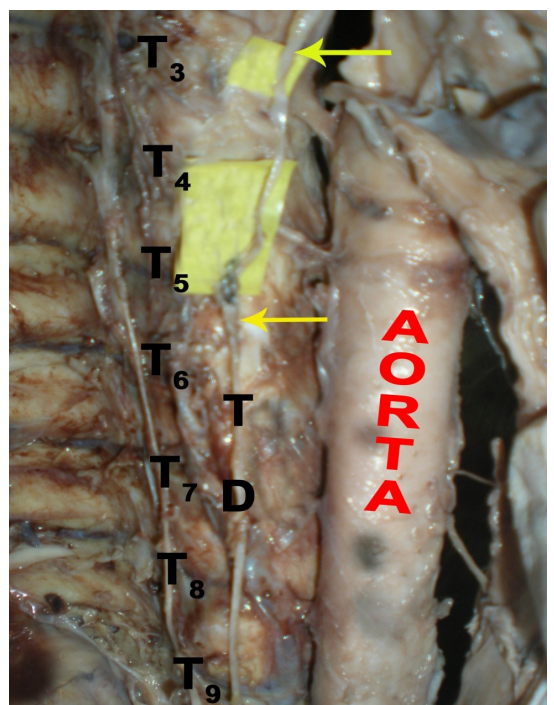

TD: THORACIC DUCT

Fig. 13: Crossing of the thoracic duct from T7 TO T3 vertebrae.

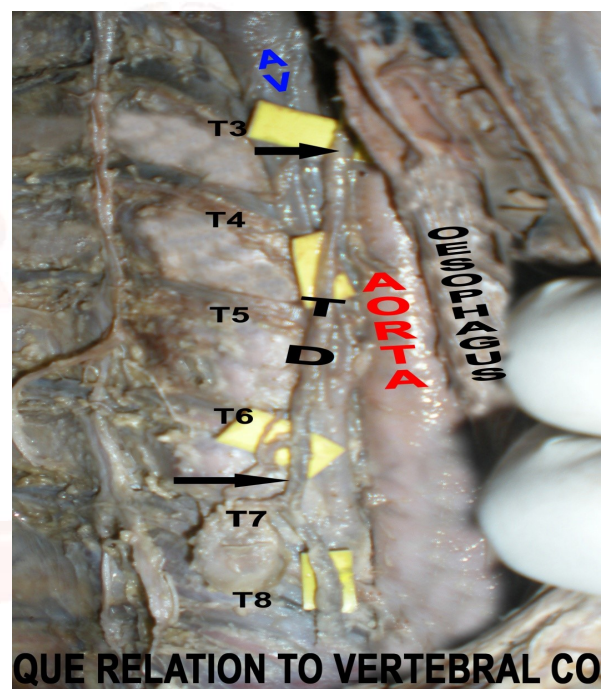

TD-THORACIC DUCT, AV-AZYGOS VEIN

Fig. 14: Left internal jugular vein type of termination of the thoracic duct.

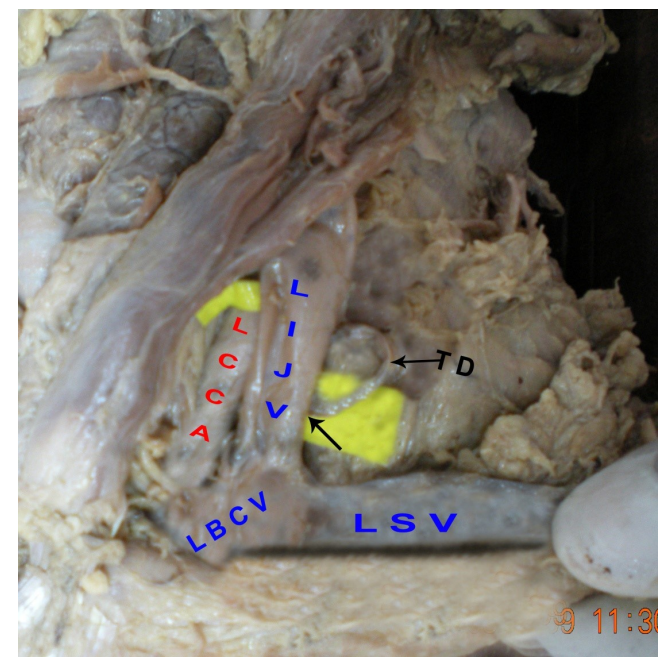

LIJV-LEFT INTERNAL JUGULAR VEIN, LSV-LEFT SUBCLAVIAN VEIN , LBCV- LEFT BRACHIO-CEPHALIC VEIN, LCCA-LEFT COMMON CAROTID ARTERY, TD-THORACIC DUCT 
Fig. 15: Termination of the thoracic duct into the left jugulo-subclavian junction.

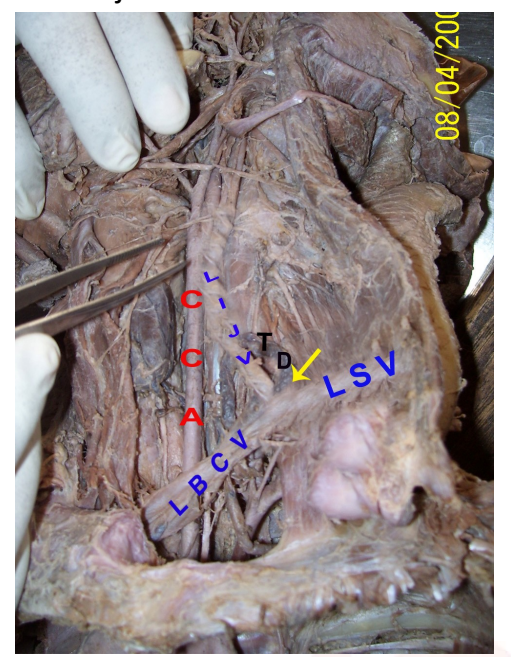

LSV LEFT SUBCLAVIAN VEIN, LBCV-LEFT BRACHIOCEPHALIC VEIN, LIJV-LEFT INTERNAL JUGULAR VEIN, LCCA-LEFT COMMON CAROTID ARTERY, TD-THORACIC DUCT

Fig. 16: Termination of the thoracic duct into the left subclavian vein.

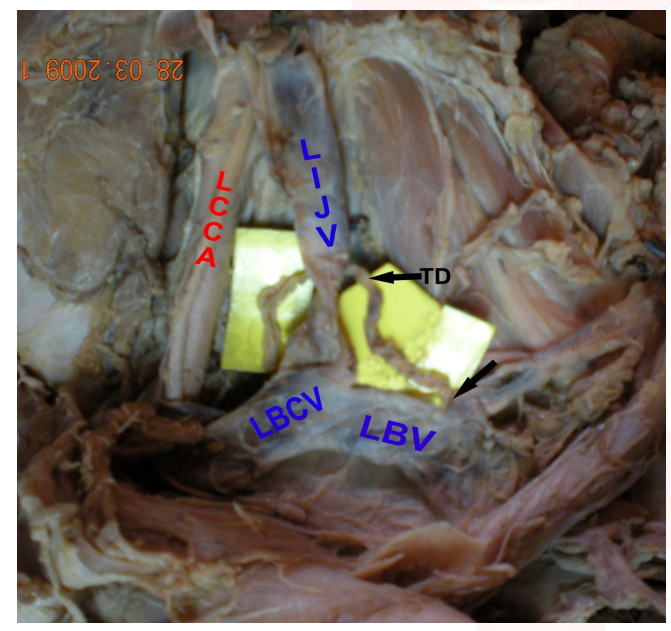

LSV-LEFT SUBCLAVIAN VEIN, LBCV-LEFT BRACHIO-CEPHALIC VEIN, LIJV-LEFT INTERNAL JUGULAR VEIN, LCCA-LEFT COMMON CAROTID ARTERY, TD-THORACIC DUCT

Fig. 17: Multiple termination of the thoracic duct.

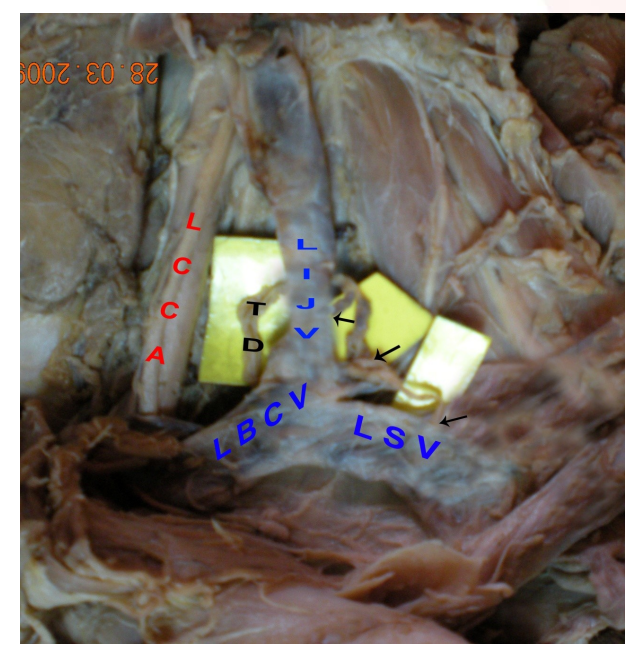

LSV-LEFT SUBCLAVIAN VEIN, LBCV-LEFT BRACHIO-CEPHALIC VEIN, LIJV-LEFT INTERNAL JUGULAR VEIN, LCCA-LEFT COMMON CAROTID ARTEY,TD-THORACICDUCT
Table 1: Position of cistern chili in relation to other studies.

\begin{tabular}{|c|c|c|c|}
\hline S.No. & $\begin{array}{c}\text { Position of cisterna } \\
\text { chyli }\end{array}$ & $\begin{array}{c}\text { Gollub. M. J. \& } \\
\text { Castellino R. A. } \\
\text { observations }\end{array}$ & $\begin{array}{c}\text { Present } \\
\text { observations }\end{array}$ \\
\hline 1 & At $\mathrm{L}_{1}-\mathrm{T}_{12}$ vertebrae & In 11 cases & In 10 specimens \\
\hline 2 & At $\mathrm{T}_{12}-\mathrm{T}_{11}$ vertebrae & In 5 cases & In 6 specimens \\
\hline 3 & ${\text { At } \mathrm{T}_{12} \text { vertebra }}$ In 2 cases & - \\
\hline 4 & At $\mathrm{L}_{2}-\mathrm{L}_{1}$ vertebrae & - & In 4 specimens \\
\hline
\end{tabular}

Table 2: Termination of cistern chili in relation to other studies.

\begin{tabular}{|c|c|c|c|c|c|}
\hline S.No. & Observer & $\begin{array}{c}\text { left Internal } \\
\text { jugulr vein } \\
\text { termination }\end{array}$ & $\begin{array}{c}\text { Left jugulo- } \\
\text { subclavian } \\
\text { termination }\end{array}$ & $\begin{array}{c}\text { Left subclavian } \\
\text { vein termination }\end{array}$ & $\begin{array}{c}\text { Left bachioceph- } \\
\text { alic vein } \\
\text { termination }\end{array}$ \\
\hline 1 & Jadnov(1959) & $48 \%$ & $35 \%$ & $9 \%$ & $8 \%$ \\
\hline 2 & Kinnaert (1973) & $36 \%$ & $34 \%$ & $17 \%$ & - \\
\hline 3 & Shuiade \& Sato (1997) & $27 \%$ & $38 \%$ & - & - \\
\hline 4 & Present study & $42 \%$ & $40 \%$ & $8 \%$ & - \\
\hline
\end{tabular}

\section{DISCUSSION}

Formation of the cisterna chyli: Cisterna chyli was formed by the union of two lumbar lymph trunks, and the intestinal lymph trunk with in the abdomen. Thoracic duct starts from its upper part. But cisterna chyli may be absent in subjects. So the generalized name, "Abdominal confluence of lymph trunks is used." whenever the abdominal confluence is in the form of el ongated saccular structure, the specific name cisterna chyli should be reserved.

In 1945, Davis had observed the cisterna chyli in only $50 \%$ percent of his observations [6]. In the presence study it was present in $44.4 \%$.

In 1978, Kubik had made observations about cisterna chyli in 70 dissections [7]. According to him cisterna chyli was absent in $80 \%$ and in our present study it was absent in 55.5\%.

In adults the cisterna chyli was present in 6 out of 15 female bodies (40\%) dissected, and was present in 14 out of 30 male bodies (46.6\%) dissected. The available data suggests that there are equal chances of presence or absence of cisterna chyli in both sexes.

In 1996, Gollub. And Castellino studied about the cisterna chyli as a potential mimic of the retrocrural lymphadenopathy in CT scans of 18 patients ${ }^{8}$. Because in the CT scan it appears as a retrocrural tubular structure. The results of their study show that cisterna chyli was variably located as detailed in the Table no.l 
Cisterna chyli when present was behind the right crus of the diaphragm. The position was variable. At the level of $L_{2}-L_{1}$ as per many text books. In the present work it was observed in 4 specimens. At the level of $L_{1}-T_{12}$ vertebrae seen in 10 specimens. At level of $\mathrm{T}_{12}-\mathrm{T}_{11}$ vertebrae seen in 6 specimens. These positions are closely related to the observations of the Gollub and Castellino (1996) [8].

Course of the thoracic duct: In 1972, Jacobson presented a very useful summary of the thoracic duct. An anatomical study was made on the thoracic duct in 100 autopsy cases. A thoracic duct was found in every case and always started below the diaphragm, passed through the posterior mediastinum in the thorax and discharged into the confluence if the veins in the left of the neck. In $4 \%$ of the cases a branch left the thoracic part of the thoracic duct at aortic arch emptied into the veins in the right side of the neck [9].

In the present study beginning of the thoracic duct conformed to the three types of Jacobson's (1972). In 20\% Type I the thoracic duct arose from the confluence of the lumbar and intestinal trunks and in Type II 60\% it was formed by the two lumbar lymph trunks and intestinal trunk had joined the thoracic duct. In Type III 20\% the thoracic duct ascended from the plexuses formed by the lumbar and intestinal trunks. These percentages are similar to the Jacobson's (1972) observations. But in the present study Type IV was not found.

In the present study duplication of the thoracic duct was observed below the crossing. The extent of duplication in relation to height of vertebral body was varying. In $24.4 \%$ extent of duplication related to the one vertebral body in $22.2 \%$ it was related to two vertebrae in $53.3 \%$ it was related to three vertebrae. No stastical data about the duplication below the crossing of the thoracic duct is available in literature except that of Hollenshead and Davis (1915) had observed the duplication of lower part of the thoracic duct in $27 \%$. It was not coinciding with the present observation.

In one specimen from a male cadaver duplication persisted in its distal part giving rise to two thoracic ducts. The percentage of occurrence was $3.3 \%$.

Int J Anat Res 2018, 6(4.2):5861-68. ISSN 2321-4287
The exact percentage of the occurrence of duplication of thoracic duct is not mentioned in many text books. This $3.3 \%$ of duplication of thoracic duct is much below the percentage quoted by Paul Van Pernis (1949), (38.7\%) and it is closely related to the Jacobson (1972) percentage (4\%).

In the present work the thoracic duct was always passing through the aortic hiatus on the right of the aorta to enter the thorax in the posterior mediastinum, ascending in front of the vertebral column on the right of the midline, between azygos vein and aorta, deep to the oesophagus up to the level of the $6^{\text {th }}$ to $7^{\text {th }}$ thoracic vertebra. There it was crossing to the left side of the midline with varying degrees of obliquity. In none of the specimen thoracic duct was crossing abruptly from right to the left of midline. The gradual mode of crossing was described by Du plessis (1975) [10]. No other statistical data about the crossing of thoracic duct available in literature except the work done by Kubik. He stated that thoracic duct is taking oblique course in $17 \%$ and bowed course in $14 \%$ of 100 autopsies studied by him.

The oblique part was measured in terms of the heights of the vertebral bodies. It was crossing from the $6^{\text {th }}$ vertebra to $4^{\text {th }}$ thoracic vertebra in 18 specimens $(40 \%)$, from $6^{\text {th }}$ thoracic vertebra to $3^{\text {rd }}$ thoracic vertebra in 9 specimens $(20 \%)$, from $7^{\text {th }}$ thoracic vertebra to $4^{\text {th }}$ thoracic vertebra in 11 specimens $(24.4 \%)$, and from the $7^{\text {th }}$ thoracic vertebra to $3^{\text {rd }}$ thoracic vertebra in 7 specimens(15.5\%).

It is evident from the above data that the crossing of the thoracic duct from right to left of the vertebral columns is oblique, instead being abrupt, having a short horizontal course.

Length of the thoracic duct: The thoracic duct is a long lymphatic vessel extending from the upper abdomen to the left side of the root of the neck.

The above data of the length pertains to the adult's subjects only. In the present work the length of the thoracic duct is ranging between $36-43 \mathrm{cms}$ in adult subjects.

An attempt was made to find out the presence of any difference in the length of thoracic duct depending on the sex of the individual. In 18 
out of 30 adult males dissected the length of the thoracic duct ranged between $35-40 \mathrm{cms}$, amounting to $60 \%$. In rest of the 12 the length was ranging between $41-45 \mathrm{cms}$, amounting to $40 \%$. Similarly in the 12 out of 15 adult female cadavers dissected, the length was ranging between $35-40 \mathrm{cms}$, about $80 \%$. In the rest of the 3 female cadavers the length was ranging between $41-45 \mathrm{cms}$, amounting to $20 \%$.

However a difference of range of $1.5-3 \mathrm{cms}$, more in the case of males may be attributed to the difference of the stature. The variations observed in the length of the thoracic duct in the present study were within the limits mentioned in the various text books. The difference of the length as per the sex is not mentioned.

\section{Termination of the thoracic duct:}

The thoracic duct as per the usual text book description mostly terminates as a single trunk into the left jugulo-subclavian venous junction, into left subclavian vein or left internal jugular vein. Just before the point of termination the left jugular lymph trunk and the left subclavian trunk join it or they drain independently. The left broncho mediastinal lymph trunk sometimes joins it.

The terminal one centimeter of the thoracic duct always presented a bicuspid valve guarding lympho venous junction. These prevent the entry of the blood into the thoracic duct under normal conditions.

The pattern of termination of the thoracic duct was almost similar to that of J danov. Jdanov in 1959 and Kinnaert in 1973 Shunada and Sato (1997), studied about thoracic duct termination [11]. Their observations were compared with the observations of the present study in the Table no: II

In the present work in 4 out of the 45 adult subjects the distal part of the thoracic duct is showing multiple terminations.

In most of the text books the percentages of the incidence of multiple termination of the thoracic duct or its relation to the sex of the individual were not available. However the present incidence of $8.8 \%$ of multiple terminations was not in inconformity with the range of $10-40 \%$ mentioned by the Kinnaret (1973).
The thoracic duct is taken up for study in view of the multiplicity of its relations to the important neighboring viscera, its vulnerability to trauma from outside as well as due to surgery involving neighboring viscera. It is likely to be caught in the fibrous scar tissue due to chronic granulomatous infections. A thorough knowledge of its origin, course and relation to the neighboring structures is very essential to give an accurate and precise, interpretation of the latest radio imaging techniques. This study is very useful for the anatomists, radiologists, surgeons during their respective procedures.

\section{Conflicts of Interests: None}

\section{REFERENCES}

[1]. Ashim Kumar Datta, Essentials of Human Anatomy $3^{\text {rd }}$ Edition, current book international (Kolkata, Bombay and Madras) PP.105, 165, 1994.

[2]. Henry Holinshed, W.: Anatomy for Surgeons, Reprinted in 1961(Volume-2) A Hoeber-Harper books: pages 193-194 and 608-610.

[3]. Jacobsson S.I.: Clinical Anatomy and Pathology of the thoracic duct. An investigation of 122 cases stocpholm; Almquist and Wiksell, 1972.

[4]. Keith L.Moore: Clinical oriented Anatomy, $3^{\text {rd }}$ edition 1992- Williams and Wilkins-London pages 25, $115,237,815-816$.

[5]. Kubik St. The variations in position and form of the thoracic part of the thoracic duct. Its skeletal relations Rofo-fortschr-Geb. Rontgenstr-Nuklearmed1975-jan;122(1):1-5.

[6]. Du Plessis, D.J. A synapsis of surgical Anatomy-11 $1^{\text {th }}$ Edition -K.M.Varghese company, Bombay 1975:34143.

[7]. Parsons, F.G. and Sargent, P.W.G.: Termination of thoracic duct. Lancet, I, 1909;1173-1174.

[8]. Healy Jc. Abdomen and pelvis, ; Gray's Anatomy, 39 $9^{\text {th }}$ Ed. Starndings, Edinburgh, Elsevier 2005,

[9]. Jdanov. D.A. Anatomical du canal thoracicque it dus princifanx colleterus lymphatigues des trome chez.Lomme. Acta Anatomica, 1959;37:20-47.

[10]. Gollub, M.J.and Castellino, and R.A. Cisterna chyli as a potential mimic of Retrocrural lymphadenopathy on CT scan-Radiology 1996;199(2):477-80.

[11]. Shunada K, Sato I. Morphological and Histological analysis of the thoracic duct at the jugulosubclavian junction in Japanese cadavers. Clinical Anatomy 1997;10:163-172.

[12]. Davis, H.K. Statistical study of thoracic duct in manAmerican Journal of Anatomy, 1915;17:211-244.

[13]. Kinnert P.K. Anatomical variations of the cervical part of the thoracic duct in man.Jour.of Anat. 1973 p.115.

[14]. Paul A.Van Pernis. Variations of the thoracic duct. Annual of Surgery. 1949;26:806-809. 